Journal of Social Sciences 4 (4): 347-351, 2008

ISSN 1549-3652

(C) 2008 Science Publications

\title{
A Qualitative Study of Factors Associated with Medical Students' Academic Success
}

\author{
${ }^{1}$ Mitra Amini, ${ }^{1}$ Mohammad Reza Dehghani, ${ }^{2}$ Javad Kojuri, ${ }^{3}$ Ali Mahbudi, \\ ${ }^{4}$ Leila Bazrafkan, ${ }^{4}$ Mahboobeh Saber, ${ }^{4}$ Zahra Karimian and ${ }^{4}$ Gholamreza Safaee Ardekain \\ ${ }^{1}$ Department of Education Development Center, Shiraz University of Medical Sciences, Shiraz, Iran \\ ${ }^{2}$ Department of Cardiology, Education Development Center, \\ Shiraz University of Medical Sciences, Shiraz, Iran \\ ${ }^{3}$ Department of English Language, Shiraz University of Medical Sciences, Shiraz, Iran \\ ${ }^{4}$ Department of Education Development Center, Shiraz University of Medical Sciences, Shiraz, Iran
}

\begin{abstract}
Problem statement: The aim of the present study was to determine the successful medical students' viewpoints on factors significant to their academic success assessed according to the students' grade point average. In this research the students with the grade point average (GPA) A (1720) were considered academically successful. Approach: The participants were 30 fifth year successful students (i.e. students with GPA, A) from Shiraz Medical School. The instrument used for the qualitative data gathering was interview. The subjects were arranged into 6 groups of 5 students followed by a discussion on reasons of their success. Five educated tutors coordinated the groups. Results: Categorizing of focus group data was done and 4 general factors including "personal abilities", "attitude, beliefs and motivation", "effort and perseverance" and "supportive factors" were found to be critical to the students' success. It is clear that all factors mentioned by students play an important role in their success in general. The similarities between the results of this study and those of others support the idea that all successful medical students share some common characteristics. Conclusion/Recommendations: The results of this study would help both medical school authorities and instructors to design strategies for more effective education. The results can also help other students to find out what might lead them to more success.
\end{abstract}

Key words: Personal abilities, attitude, beliefs and motivation, effort and perseverance, supportive factors

\section{INTRODUCTION}

There are more or less comparable criteria for the admission of medical students in different countries, including academic ability, insight into medicine and interests, personality, motivation and linguistic and communications skills $^{[1-4]}$.

The aim of a medical school admission procedure is to select those who will perform well as undergraduates and become good doctors in the future and to exclude those who will bring the profession into disrepute $^{[5]}$.

In Iran, this process is carried out through a national university entrance exam that conducted once yeas and those admitted are the top high school students.

This admission is extremely competitive conducted once a year. After entering medical school, the students have to study 7 years for getting MD (Doctor of medicine) degree and practice as a general practitioner.

In spite of this difficult selection process, some of the students selected are not successful. Accordingly, the aim of the present study was to determine the successful medical students' point of view on factors significant to their success.

\section{MATERIALS AND METHODS}

Thirty fifth year successful students (i.e., students with GPA, A) from Shiraz Medical School participated in this study. A focus group design investigated the their viewpoint on academic success which was defined as the Grade Point Average (GPA) A. Focus groups are particularly suitable for obtaining different viewpoints on pertinent topics. That is, the purpose of using a focus

Corresponding Author: Mitra Amini, Education Development and Research Center, Shiraz Medical School, Building No 3,seventh flour ,Zand Street,Shiraz,Iran Tel: 00989173132902 Fax:00987112333064 
group is to obtain information of qualitative research from a limited number of people. In this study, semi structured and in depth interview was used for qualitative data gathering technique. Students were selected by maximum variation sampling that important variation in parameters such as gender was achieved.

Procedure: The subjects were arranged into 6 groups of 5 students. At first 5 open-ended questions related to their academic success were asked:

- How do you feel about being a medical student?

- How do you feel about medicine in general?

- Do you believe that you are a successful student?

- What accounts for your academic success?

- What can maintain your success in future?

The first two questions were general questions used to stimulate discussion and encourage interaction in a normal manner with observers.

Data analysis: The following steps were undertaken for data analysis:

- Immediate debriefing after focus group discussions

- Listening to videotapes and transcribing the contents

- Comparing the content of the tapes with observations

We used this to check the contents of the videotapes with the students' gestures, behavior, nonverbal communications skills...). Five educated tutors coordinated the groups. Categorizing of focus group data was done, using qualitative content analysis suggested by ${ }^{[6,7]}$.

The entire transcript was evaluated line by line and each significant statement, according to the topics, was selected and categorized into codes.

The codes were compared based on similarities and differences and finally the categories were formatted into 4 themes for success in the present time and for the maintenance of success in future. The data were submitted to 4 assessors to check for the validity and reliability of the codes.

\section{RESULTS}

This qualitative analysis led to the emergence of four themes for the students' success:

- Personal abilities

- Attitude, beliefs and motivation
- $\quad$ Effort and perseverance

- Supportive factors

Personal abilities: This factor was emphasized by all focus groups. Almost all of the successful students reported that personal abilities were one of the most important factors for academic success in a medical school. They argued that such abilities were critical for studying medicine and communicating with patients.

One of the students said: Studying medicine is different from studying other sciences. I think that personal abilities are very important for communication with patients, diagnosis and management.

Another student stated: In studying medicine, personal characteristics such as intelligence, creativity and concentration are very important. On first days of studying medicine I was anxious about every thing but now I think that my personal skills helped me to overcome my nervousness.

In this connection, what all of the students agreed on was the importance of self-confidence in success.

Attitude, beliefs and motivation: A view frequently stressed by medical students in focus group sessions was that positive attitude to their profession was a significant factor in their academic success.

One of them asserted: Medicine is a profession not a job. Positive attitude to being a good physician helped me to be a successful student.

Another student argued that: "Positive attitude", "feel of usefulness motivated me to be successful in my academic life

Effort and perseverance: The category effort and endurance emerged from all focus group discussions and almost every student in the focus group sessions emphasized its significance.

One of the students said: I have learnt so many things in basic courses but when attending clinical wards I found that I had to try more and more.

Another student argued: Medicine is different from other sciences and being a medical student means that we have a full time job. We should try more than other students; we should stay up late in the night and this needs effort and endurance. 
Another student maintained: Medicine allows for my personal development and inspires my future academic life; therefore, I work hard, as becoming a physician is exciting and needs effort and perseverance.

Another student claimed: You have medicine and you have Life. Working from 6:30 in the morning until midnight in hospitals needs perseverance as in a marathon.

Supportive factors: Family support, support from medical school authorities, friends were reported important for success by students.

One of the students said: Family support is very important for me. My brother is a general practitioner and supports me in all stages of my education. I think that all of the students in medical school need a person to guide them at any stage of their medical education.

Another student reported the role of medical authorities in this way: $I$ think that the role of an authority is now more audit than support. I need their support for both educational and recreational affairs.

\section{DISCUSSION}

The results of the students' viewpoints toward academic success revealed that 4 themes "personal abilities", "attitude and beliefs and motivation", "effort and endurance" and "supportive factors" were considered significant for academic success.

The medical students clearly emphasized that their personal abilities such as creativity, self-confidence and concentration were key factors to their success. A systematic review of literature in Nottingham showed that eight subscales had emerged consistently as predictor of success in medical training: "dominance", "tolerance", " sociability" , " self-acceptance"," wellbeing", "responsibility", "achievement via conformance" and "achievement via independence" ${ }^{\text {[8] }}$.

Positive attitude, beliefs and motivation in medicine have been an issue of concern for many years as it has been shown to improve learning ${ }^{[9]}$.

Pintrich identified 3 main categories of concepts relevant to motivation in an educational setting:

- Personal beliefs in the abilities to undertake the activity

- Reasons or purposes for engagement.

- Affective reaction in relation to the activity ${ }^{[10]}$

Sobral reported that autonomous motivation had close relationship with measures of self regulation of learning and academic success in the context of a demanding medical program in medical students ${ }^{[9]}$.

Some studies have reported that attitude would predict post-graduate clinical competence ${ }^{[11-16]}$.

The third theme elicited from the focus groups was effort and perseverance. Effort was mentioned more important than intelligence in medical schools.

A study on the characteristics of a good doctor in Liverpool medical school showed that 10 factors were important from students' viewpoint, the first of which was: "working hard over long hours, including on call $^{[17]}$. All of our successful students know that without working hard in wards and studying most of the time they can not be good doctors.

The last theme that nearly most of the students pointed out was university and family support.

In a qualitative study about balancing work, family and other lifestyle aspects in Australian medical schools some students reported that they would like to be near one of their parents when they have kids, as they saw family support as an important factor in helping them cope with being in dual-career ${ }^{[18]}$. In the past many male doctors worked extended hours with the support of a wife who was not employed outside the home ${ }^{[19,20]}$.

Nowadays most of medical students no longer expect that their spouse would provide this level of support. Many expect their spouses to share family responsibilities, as well as contributing to family income.

The theory that emerged in our study indicates that some academic and non academic factors lead to success in the medical school.

After there results we designed academic success tips in our medical school. These tips were used for educating students by their successful peers. We designed a workshop about "how becomes a successful student in medical school" at the beginning of first trim nester for first year medical students.

Also a unit named "consultancy center for students" was developed.

One of the major responsibilities of this center is to encourage participation of unsuccessful students and help them to become successful.

Another center in education development center was created as "students' education group" that helps students to learn about new educational menthols and study skills.

\section{CONCLUSION}

It is clear that all factors mentioned by the students play important roles in their academic success in general. The similarities between the results of this 
study and those of others confirmed that some of the factors are universal for academic success in medicine.

The results of this study not only would help the medical school planners and instructors to design strategies for more effective education, but also can motivate other students to find out what to do for more success.

Competing interest: We conducted this study in response to the Shiraz medical school manager as they considering academic success in studying medicine is a very important factor that straightly leads to improved community health.

The decision to submit the paper has been solely with the authors. The finding of the study that leads to developing a consultant center had no effect on the authors' promotion or salary

\section{ACKNOWLEDGEMENT}

We are much obliged to thanks our students for participating in this study.

\section{REFERENCES}

1. McManus, I.C., P. Richards, B. Winder, W. Sproston and V. Styles, 1995. Medical school applicants from ethnic minority groups: Identifying if and when they are disadvantaged. Br. Med. J., 310: 496-500. http://www.bmj.com/cgi/content/full/310/6978/496.

2. Esmail, A., P. Nelson, D. Primarolo and T. Toma, 1995. Acceptance into medical school and racial discrimination. Br. Med. J., 310: 501-502. http://www.pubmedcentral.nih.gov/articlerender.fc gi? $\operatorname{artid}=2548874$.

3. Lumb, A. and A. Vail, 2000. Difficulties with anonymous short-listing of medical school applicants and its effects on candidates with nonEuropean name: Prospective cohort study. Br. Med. J., 320: 82-85.

http://www.bmj.com/cgi/content/abstract/320/7227/82.

4. MCManus, I.C., 1998. Factors affecting likelihood of applicants offered a place in medical schools in the United Kingdom in 1996 and 1997: Retrospective study. Br. Med. J., 317: 1111-116. http://www.ncbi.nlm.nih.gov/pubmed/9784446.

5. Mary Ann Lumsen, Miles Bore, Keith Miller, Rachael Jack and David Powis, 2005. Assessment of personal qualities in relation to admission to medical school. Med. Educ., 39: 258-265. DOI: 10.1111/j.1365-2929.2005.02087.x.
6. Graneheim, U.H. and B. Lundman, 2004. Qualitative content analysis in nursing research: Concepts, procedures measures to achieve trustworthiness. Nurse Educ. Today, 24: 105-112. http://www.ncbi.nlm.nih.gov/pubmed/14769454.

7. Stewart, D.W. and P.N. Shamdasani, 1990. Analyzing Focus Group Data. In: Focus Groups: Theory and Practice, Shamdasani, P.N. (Ed.). Sage Pulications, Newbury Park,ISBN: 10: 0803933908, pp: 160.

8. Eamonn Ferguson, David James and Laura Madeley, 2002. Factors associated with success in medical school: Systematic review of the literature. Br. Med. J., 324: 952-957. http://www.bmj.com/cgi/content/full/324/7343/952.

9. Sorbal, D.T., 1991. What kind of motivation derives medical students' Learning quests? Med. Educ., 38: 950-957.

http://www3.interscience.wiley.com/journal/11877 8811/abstract.

10. Pintrich, R.R., 1991. Editor's comments. Educ. Psychol., 26: 199-205.

11. Hojat, M., B.D. Bornatein and J.J. Veloski, 1988. Cognitive and non-cognitive factors in predicting the clinical performance of medical school graduates. Med. Educ., 63: 323-325.

http://www.ncbi.nlm.nih.gov/pubmed/3357184.

12. Gonnella, J.S. and M. Hojat, 1983. Relationship between performance in medical school and postgraduate competence. J. Med. Educ., 58: 679-685. http://www.ncbi.nlm.nih.gov/pubmed/6887211.

13. Johnson, V. and D. Miller, 1963. Correlation between performance in medical school and in residency training. Med. Educ., 38: 591-595.

14. Prat, H.M. and R.J. Markert, 1993. Predicting the first-year performances of international medical graduates in an internal medical residency. Acad. Med., 11: 856-858.

http://www.ncbi.nlm.nih.gov/pubmed/8216659.

15. Markert, R.J., 1993. The relationship of academic measures in medical school to performance aftergraduation. Acad. Med., 68: S31-S34. http://www.ncbi.nlm.nih.gov/pubmed/8141856.

16. Richards, J.M., C.W. Taylor, P.B. Price and T.L. Jacobsen, 1965. An investigation of the criterion problem for one group of medical specialists. J. Applied Psychol., 49: 79-90. http://www.ncbi.nlm.nih.gov/pubmed/14318072.

17. Maudsley, G., E.M. Williams and D.C. Taylor, 2007. Junior medical students' notion of a good doctor and related expectation: A mixed methods study. Med. Educ., 41: 476-486.

http://www.ncbi.nlm.nih.gov/pubmed/17470077. 
18. Tolhurst, H.M. and S.M. Stewart, 2004. Balancing work, family and other lifestyle aspects: A qualitative study of Australian medical students' attitudes. Med. J. Aust., 181: 361-364. http://cat.inist.fr/?aModele $=$ afficheN\&cpsidt $=16146362$.

19. Fett, I., 1976. The future of women in Australian medicine. Med. J. Aust., 2: 33-39.

http://www.ncbi.nlm.nih.gov/pubmed/1012123.
20. Dennerstein, L., P. Lehert and R. Orams et al., 1989. Practice patterns and family life-a survey of Melbourne medical graduates. Med. J. Aust., 151: 386-390.

http://www.ncbi.nlm.nih.gov/pubmed/2796814. 